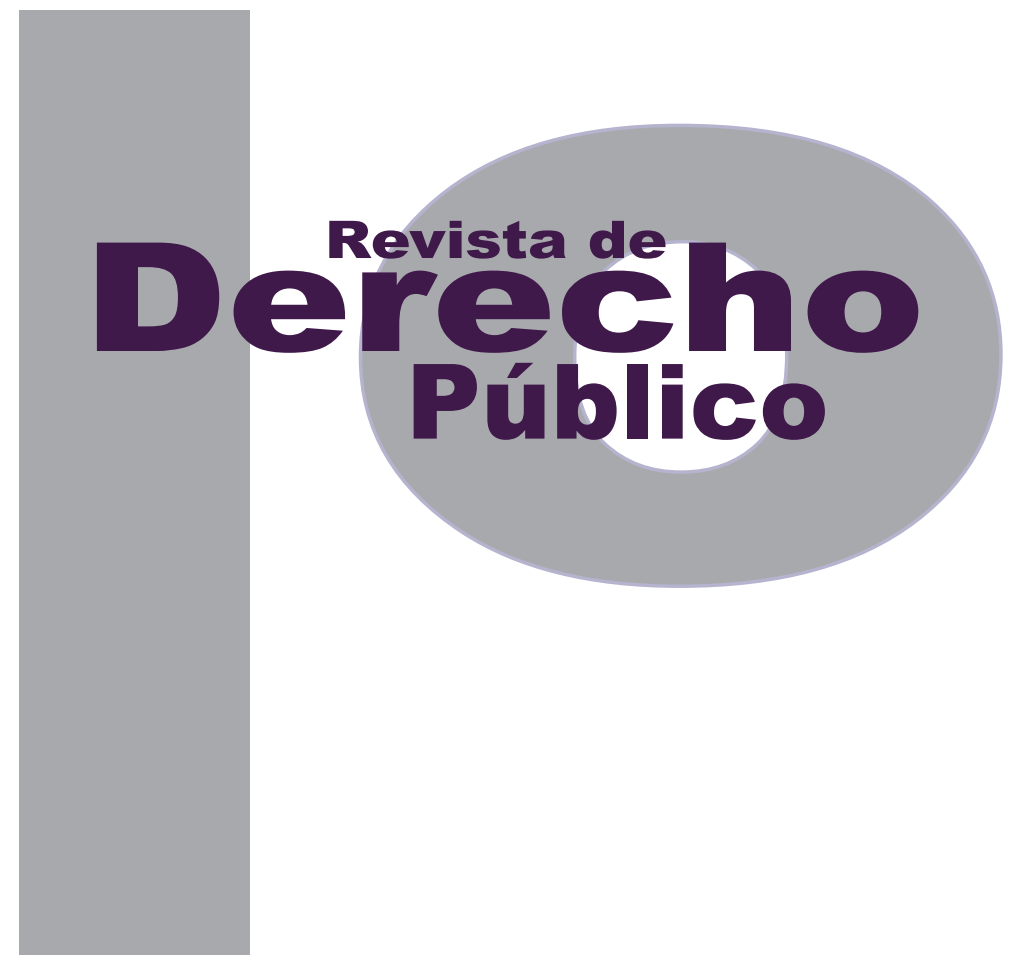

\title{
EL DERECHO A LA INTIMIDAD DEL TRABAJADOR COMO RESTRICCIÓN AL PODER SUBORDINANTE DEL EMPLEADOR: EL INCIPIENTE DESARROLLO EN COLOMBIA FRENTE AL DERECHO COMPARADO
}

\author{
Diana Estefany Segura Castañeda
}

\author{
Revisión de tema
}

DOI: http://dx.doi.org/10.15425/redepub.34.2015.03

Universidad de los Andes

Facultad de Derecho

Revista de Derecho Público N. ${ }^{\circ} 34$

Enero - Junio de 2015. ISSN 1909-7778 


\title{
El derecho a la intimidad del trabajador como restricción al poder subordinante del empleador: el incipiente desarrollo en Colombia frente al derecho comparado
}

\section{Resumen}

Las siguientes páginas intentarán presentar algunas perspectivas a nivel internacional frente a la protección del derecho a la intimidad en el trabajo, a través de ejemplos y decisiones tomadas por diferentes tribunales y entidades administrativas. En este documento se realiza una descripción general de la protección laboral del derecho a la intimidad, a partir del momento en que se aspira a un cargo mediante un contrato de trabajo y hasta después de la terminación, no solo en Colombia sino a través del derecho comparado, para ilustrar cómo es su protección en otros países, concluyendo que nosotros no tenemos una protección tan fuerte de este derecho.

Palabras clave: derecho a la intimidad del trabajador, subordinación del empleador, límites al poder de vigilancia en el trabajo, tipos de información relacionada con el derecho a la intimidad, derechos fundamentales en el lugar de trabajo.

\section{The Employee's privacy right as a limit of employer's subordinate power: the incipient development in Colombia against comparative law}

\begin{abstract}
The following pages try to indicate some international perception and protection of the right to privacy at the workplace, trough examples and cases decided by different tribunals and administrative entities. The document makes a general description of the intimacy worker protection since the application to work, until after the breach of the contract not also in Colombia, because it considers different cases of the comparative law to make an illustration of how different countries make similar consideration to protect these right, to conclude that we don't have a such a strung protection of this right.

Keywords: Worker's intimacy right, employer subordination, limits of the employer vigilance at workplace, types of information related with the intimacy right, fundamental rights at workplace.

\section{O direito à intimidade do trabalhador como restrição ao poder subordinante do empregador: o incipiente desenvolvimento na Colômbia frente ao direito comparado}

\section{Resumo}

As seguintes páginas tentarão apresentar algumas perspectivas a nível internacional frente à proteção do direito à intimidade no trabalho, através de exemplos e decisões tomadas por diferentes tribunais e entidades administrativas. Neste documento se realiza uma descrição geral da proteção laboral do direito à intimidade, a partir do momento em que se aspira a um cargo mediante um contrato de trabalho e até depois do término, não só na Colômbia senão através do direito comparado, para ilustrar como é sua proteção em outros países, concluindo que nós não temos uma proteção tão forte deste direito.

Palavras-chave: direito à intimidade do trabalhador, subordinação do empregador, limites ao poder de vigilância no trabalho, tipos de informação relacionada com o direito à intimidade, direitos fundamentais no lugar de trabalho. 


\title{
El derecho a la intimidad del trabajador como restricción al poder subordinante del empleador: el incipiente desarrollo en Colombia frente al derecho comparado*
}

\author{
Diana Estefany Segura Castañeda**
}

\begin{abstract}
SUMARIO
Introducción - I. DERECHO A LA INTIMIDAD - II. DEL PODER SUBORDINANTE DEL EMPLEADOR - A. Del respeto por los derechos fundamentales en el ámbito de la relación laboral - B. Del choque entre el derecho a la libertad de empresa (poder subordinante) y el derecho a la intimidad del trabajador - III. ASPECTOS DE PROTECCIÓN DEL DERECHO A LA INTIMIDAD EN EL ÁMBITO LABORAL - A. De la protección a la intimidad al momento de aspirar a un cargo - B. Del derecho a la intimidad en la ejecución del trabajo - 1. Posibilidad de vigilar al trabajador en el trabajo - 1.1. Control audiovisual - 1.2. Control sobre uso de herramientas de trabajo - 2. Del derecho a la intimidad respecto a las condiciones de salud del trabajador - 3. De la información reportada en el expediente del trabajador - C. De la protección de la intimidad del trabajador a la terminación del contrato de trabajo - IV. CONCLUSIONES - Referencias.
\end{abstract}

* Cómo citar este artículo: Segura Castañeda, D. E. (Junio, 2015). El derecho a la intimidad del trabajador como restricción al poder subordinante del empleador: el incipiente desarrollo en Colombia frente al derecho comparado. Revista de Derecho Público, 34. Universidad de los Andes (Colombia).

** Abogada, especialista en derecho laboral y relaciones industriales, y estudiante de la Maestría en Derecho con énfasis en derecho al trabajo de la Universidad Externado de Colombia. Docente-investigadora de la misma universidad, asesora jurídica de la Sociedad Colombiana de Anestesiología y Reanimación (s.c.a.r.e.). Correo diana.segura@uexternado.edu.co 
Introducción

El derecho a la intimidad como límite al poder subordinante del empleador ha sido desarrollado incipientemente en Colombia, donde encontramos pronunciamientos judiciales aislados, en diferentes esferas, en contraposición con el desarrollo que ha tenido el tema en el continente europeo y en Estados Unidos. A nivel regional, en América Latina tampoco se cuenta con un dictamen al respecto, a diferencia de Europa donde la Corte Europea de Derechos Humanos (2007) sí aporta distintos precedentes judiciales. ${ }^{1}$

En consecuencia, la regulación de los límites del poder subordinante del empleador en razón de la intimidad del trabajador se encuentra en la doctrina ${ }^{2} \mathrm{o}$ en precedentes judiciales, y para la

1 El caso al que se hace referencia con mayor frecuencia para el tema de monitoreo de conversaciones es Copland vs. Reino Unido, en el que se examina el monitoreo sin autorización de las llamadas, correos electrónicos y sitios de Internet visitados por una trabajadora, los cuales eran supervisados por el Deputy Principal, su jefe inmediato.

El Tribunal examina la transgresión del derecho a la privacidad, la posibilidad de incumplimiento del contrato por parte del empleador por violar el principio de confianza en su trabajador sin tener una duda razonable, y la Ley de Protección de Datos de 1984, concluyendo que el alcance del derecho a la intimidad comprende las llamadas efectuadas desde el teléfono de la empresa y del correo, por una expectativa de intimidad del trabajador, motivo por el cual al momento de determinar el daño de la accionante indicó que por el estrés causado por el monitoreo de las conversaciones se le reconocían 3000 euros como indemnización por daño no pecuniario.

2 La Organización Internacional del Trabajo (ОІт) elaboró en 1997 un documento denominado Repertorio de recomendaciones prácticas sobre la protección de datos personales de trabajadores, el cual no tiene fuerza vinculante pero sí prevé diferentes reglas sobre la protección de la intimidad de los trabajadores, sin desconocer la facultad de control del empleador. Similar trabajo fue desarrollado en el Reino Unido con The Employment Practices Code, elaborado por la Information Comissioner's office, una autoridad independiente encargada de proteger la privacidad de datos y la defensa de la información, con el ánimo de ayudar a los empleadores a cumplir con lo establecido en la Ley de Protección de Datos de 1998 y ofrecerles reglas y recomendaciones para que no trasgredan derechos fundamentales de los trabajadores en aspectos como los archivos documentales, la vigilancia en el trabajo y la protección de datos referentes a su salud. solución de casos dentro de nuestro derecho interno se debe acudir al tratamiento que se le ha dado a nivel internacional, con las consideraciones relativas a la situación concreta, y a reglas o parámetros tomados en cuenta en la ponderación de los derechos del trabajador y del empleador en el marco de su libertad de empresa y organizativa.

El presente escrito expone una compilación doctrinaria y jurisprudencial del tema a nivel internacional, teniendo como punto de partida el concepto del derecho a la intimidad del trabajador y el ejercicio del poder subordinante del empleador, para determinar cuáles son los límites que se han establecido entre uno y otro derecho a través de las diversas etapas del vínculo contractual laboral.

\section{DERECHO A LA INTIMIDAD}

El derecho a la intimidad ha sido definido como el derecho a no ser molestado, a guardar reserva, a mantener una vida privada sin la injerencia de otras personas. Adquiere relevancia cuando aparece la tensión individuo-comunidad, en la medida en que los hechos 0 actividades personales no conocidos por los demás resultan sustraídos y se hacen valer frente a otros, causando perturbación al momento de ser revelados (Gutiérrez, 2001, pp. 32-35).

El derecho aludido comprende el secreto por la vida íntima, la facultad del individuo de controlar la divulgación de información sobre sí mismo y el deber de los demás agentes de respetar 
la intimidad (Gutiérrez, 2001, p. 38). El control de la información es considerado uno de los elementos más importantes del derecho a la intimidad. El individuo tiene derecho a que se mantengan ocultos aspectos de su vida privada que no ha comunicado a nadie, y a controlar el manejo de información que pueda ser obtenida por un tercero (Escobar y Marulanda, 2004, p. 40) como sucede, por ejemplo, en el caso del médico que por su profesión conoce la historia clínica del paciente.

En la época contemporánea el desarrollo del derecho a la intimidad ha sido atribuido, en parte, al auge de los medios tecnológicos y de las comunicaciones, como quiera que a través de ellos es más fácil difundir aspectos de la vida privada de los individuos, al tiempo que permiten controlar las actuaciones de las personas, por ejemplo, mediante grabaciones y el monitoreo de conversaciones.

El derecho a la intimidad figura en instrumentos normativos de carácter universal, regional y local. Desde la concepción del Estado liberal se propugnó porque la intimidad del individuo fuere garantizada como un derecho de primera generación, relacionado con la libertad, al garantizársele la no intromisión por parte de los demás.

La Declaración Universal de Derechos Humanos en su artículo $12,{ }^{3}$ refiere a cuatro ámbitos que hacen parte de la intimidad del individuo:

3 Artículo 12. Nadie será objeto de injerencias arbitrarias en su vida privada, su familia, su domicilio o su correspondencia, ni de ataques a su honra o a su reputación. Toda persona tiene derecho a la protección de la ley contra tales injerencias o ataques. su vida privada, su familia, su domicilio y su correspondencia. Esta disposición es tomada de manera integral en el artículo 17 del Pacto Internacional de Derechos Civiles y Políticos, al igual que en el artículo 11 de la Convención Americana de Derechos Humanos, y de manera parcial en el artículo 5 de la Declaración Americana de Derechos y Deberes del Hombre al señalar que existe protección a la vida privada y familiar.

El Convenio Europeo de Derechos Humanos en su artículo 8 , al referirse al derecho al respeto a la vida privada y familiar, determina en el numeral segundo que la injerencia de las autoridades públicas debe ocurrir de manera excepcional, debe ser prevista en la ley, y solo en caso de ser necesaria como medida de salvaguarda de la seguridad nacional, el bienestar económico del país, la protección de la salud, entre otros aspectos (Consejo de Europa, 1950). Como consecuencia lógica, si la intromisión de las autoridades públicas es excepcional, la injerencia de los particulares no tendría cabida, o en el caso de ser permitida debería salvaguardar bienes jurídicos iguales o mayores a los señalados para la intrusión de las autoridades públicas.

En ese sentido, la Asamblea General de la onu profirió la Resolución A/RES/68/167, aprobada el 18 de diciembre de 2013, relativa al derecho a la privacidad en la era digital. En ella se hace explícito que la vigilancia e interceptación ilícita o arbitraria de comunicaciones, así como la recopilación ilícita de datos personales constituyen actos de intrusión grave, y violan el derecho a la intimidad; en consecuencia, no cualquier interceptación de comunicaciones ni recopila- 
ción de datos afecta el derecho a la intimidad, sino aquellas que se realizan de manera ilícita. Adicionalmente, señala que las consideraciones de seguridad pública no pueden sobreponerse al ejercicio de derechos fundamentales (ONU, 2013).

Este derecho se encuentra reconocido en instrumentos internacionales de derechos humanos que en Colombia hacen parte del bloque de constitucionalidad, como son el artículo 17 del Pacto Internacional de Derechos Civiles y Políticos y el artículo 11 de la Convención Americana sobre Derechos Humanos, que establecen que nadie podrá ser objeto de injerencias arbitrarias en su vida privada, su familia, domicilio o correspondencia.

No obstante, el contenido del derecho ha sido determinado por cada país de forma independiente, y la protección puede ser más amplia en algunas legislaciones.

En Colombia el derecho a la intimidad tiene rango constitucional, está contemplado en el artículo 15 en que se indica a grandes rasgos que toda persona tiene derecho a su intimidad personal y familiar, por lo que la doctrina y la jurisprudencia han sido las encargadas de determinar el alcance del derecho, su núcleo esencial y sus límites.

En cuanto a su contenido básico, resulta importante citar la sentencia C-540 de 2012 de la Corte Constitucional, en la que se señala como rasgo esencial el espacio medular donde la personalidad tiene plena libertad, por encontrarse exclui- da del dominio público, por lo que su protección se garantizará prohibiendo la intrusión irracional en la información reservada de cada persona, así como su divulgación o tergiversación.

En cuanto a los límites, jurisprudencialmente se ha reconocido que solo puede ser objeto de limitaciones cuando se encuentra enfrentado con otro derecho, lo que involucra criterios de ponderación para determinar si existe transgresión o no al derecho a la intimidad. ${ }^{4}$ Recientemente, al examinar el tema de la posibilidad de conocer la historia clínica de un paciente, se consolidó la postura según la cual la intensidad de protección del derecho a la intimidad guarda relación con el tipo de información involucrada, aspecto que también había sido tenido en cuenta por la Corte Constitucional al señalar que la información relacionada con el ámbito de trabajo tenía repercusión social, y en esa medida no tenía una protección tan elevada como la del domicilio personal (sentencia T-768 de 2008).

Según la sentencia T-427 de 2013, existen cuatro tipos de información: la pública, la semiprivada, la privada y la reservada. La pública no tiene reserva alguna y puede ser conocida por cualquier persona, por ejemplo, la información relativa a un acto administrativo o a una sentencia judicial; la semiprivada es información que solo es manejada por autoridades competentes pero que se puede suministrar al público, por

Adicional a los criterios de ponderación de necesidad, idoneidad y proporcionalidad, en sentencia T-787 de 2004 la Corte Constitucional también hizo alusión al principio de libertad, de conformidad con el cual la divulgación de datos personales requiere un consentimiento libre, previo y expreso, y al principio de veracidad, que implica que los datos correspondan a situaciones reales. 
ejemplo, la relacionada con el comportamiento financiero; la privada es aquella que por encontrarse en un ámbito reservado solo puede ser conocida de manera excepcional; mientras que la reservada es aquella que solo es conocida por su titular, en la medida que cualquier irrupción conlleva una lesión de derechos, indicando la Corte Constitucional, a manera de ejemplo, que de ella hacen parte la orientación sexual y la información genética.

De lo anterior se deduce que solo en el ámbito de la información pública no existe riesgo de lesionar el derecho a la intimidad, mientras que en los otros tipos de información sí se puede presentar una transgresión de este derecho, bien porque sea conocida por personas no autorizadas, porque no se den los supuestos de excepcionalidad para conocerla, o porque se encuentre en un ámbito reservado exclusivo del individuo.

En el ámbito del trabajo existen estos cuatro tipos de información sobre el trabajador, de los cuales a modo de ejemplo se citan los siguientes: pública, el título obtenido para desempeñar una profesión u oficio; semiprivada, el pago en nómina; privada, el expediente contentivo del historial laboral, que solo puede ser conocido por el empleador, por su representante o por el trabajador titular; y reservada, como las preferencias religiosas.

De manera que, adicionalmente, al evaluar el tipo de información para determinar la existencia de una transgresión al derecho a la intimidad, resulta necesario examinar los alcances del poder subordinante del empleador y la facultad que este le otorga para conocer diferentes tipos de información sobre el trabajador.

Por ejemplo, frente a la regulación de otros países, Pecorella y De Ponti (2010, p. 591) se refieren al caso italiano en el que la Corte Constitucional, en sentencia del 26 de febrero de 1993, indicó que el artículo 15 de la Constitución en el que se dispone lo relativo al derecho a la intimidad, correspondía a un derecho inviolable sobre el cual no cabía limitación salvo lo dispuesto en la ley, al considerarse como parte necesaria del espacio vital de toda persona, sin el cual no puede desarrollarse de acuerdo con la dignidad del ser humano, de manera que su carácter de inviolabilidad le da prevalencia sobre otras libertades o poderes frente a los cuales pueda entrar en conflicto. Entonces, no se justifica la interferencia del empleador en las comunicaciones por ser el dueño de los instrumentos y herramientas de trabajo, como quiera que el derecho a la intimidad involucra las características de ser intrasmisible, irrenunciable, indisponible e imprescriptible. ${ }^{5}$ Mientras que en el caso de

5 En concordancia con lo anterior, el Estatuto del Trabajo de Italia, Ley 300 de 1970, previó en su artículo 4 que estaba prohibido el uso de equipos audiovisuales y equipos de monitoreo para controlar la actividad de los trabajadores, salvo que existiera un acuerdo previo entre los representantes sindicales de la empresa y el empleador. En consecuencia, el empleador, motu proprio, no podría abrogarse la facultad de disponer en documento adjunto al contrato de trabajo autorización por parte del trabajador para la instalación de cámaras de monitoreo. Desde 1970 el legislador italiano previó la posibilidad de establecer un control por medios tecnológicos al trabajador, e identificó la protección de sus derechos de dignidad, libertad y autonomía como elementos de la prestación humana del servicio (Pecorella y De Ponti, 2010, p. 612). La limitación en la vigilancia se manifiesta en este artículo de manera exclusiva para el monitoreo por medio de equipos, mientras que deja abierta la posibilidad de control de manera presencial por el empleador. Lo controversial del tema es que se ha entendido de manera amplia el sistema de monitoreo ilegal, llegando a incluir, por ejemplo, el uso de tarjetas para controlar los horarios de trabajo, pero el sistema personal y sin maquinaria a través de terceros o de inspec- 
España, las controversias surgidas entre el derecho a la libertad de empresa, por el cual se manifiesta el control subordinante del empleador, y el derecho a la intimidad del trabajador, se examinan desde una perspectiva de igualdad estableciendo límites entre ellos mismos, como se verá posteriormente.

\section{DEL PODER SUBORDINANTE DEL EMPLEADOR}

Cuando el empleador suscribe un contrato de trabajo con el trabajador surge el poder subordinante por parte del primero y el deber de obediencia por parte del segundo. El poder subordinante vincula la facultad de dirección y de vigilancia que hace referencia a la capacidad para organizar y ordenar el trabajo en la empresa, en cuanto a las circunstancias de modo, tiempo y lugar (Melis, 2010, p. 131). Este poder subordinante se enmarca entonces dentro del ámbito laboral y no puede traspasar otros aspectos de la vida del trabajador, e involucra la facultad de dar órdenes, de impartir instrucciones que se deben ejecutar al interior de la empresa, la reglamentación sobre la forma de prestación del servicio, y contiene además la facultad de vigilar, controlar y sancionar al trabajador (Hernández, 1997, pp. 405-406).

Ahora bien, ninguna orden impuesta por el empleador como facultad del poder de dirección puede ir en contra de los derechos de los trabajadores; no podrá entonces tampoco proferir instrucciones arbitrarias o incoherentes que lesionen principios constitucionales que tienen superioridad en el ordenamiento jurídico, causando perjuicios sobre el trabajador, de manera que inicialmente se puede señalar que el primer límite al poder directivo, organizativo y sancionatorio del empleador lo constituye la protección de los derechos fundamentales del trabajador.

Entonces, ¿cuándo se pueden lesionar los derechos de los trabajadores, ante el control o vigilancia del empleador? y en sentido concreto, ¿cuándo se puede desconocer el derecho a la intimidad del trabajador?, ¿está facultado el empleador para conocer el estado de salud de los trabajadores?, ¿está facultado el empleador para controlar el uso de los instrumentos por él suministrados, tales como computadores y teléfonos, mediante la interceptación de llamadas, correos electrónicos institucionales o archivos que se encuentren en los computadores de los trabajadores?, ¿está facultado el empleador para averiguar aspectos íntimos de la vida de un aspirante a trabajador o de sus familiares en un proceso de selección?, ¿tiene el empleador la posibilidad de instalar cámaras de seguridad para controlar la ejecución de las labores por parte del trabajador? o por el contrario, ¿existe una limitación objetiva frente a la injerencia del empleador en la vida íntima del trabajador en el sitio de trabajo o en los aspectos relacionados con el trabajo? A las preguntas anteriores se pretende dar respuesta a continuación. 


\section{A. Del respeto por los derechos fundamentales en el ámbito de la relación laboral}

El trabajador es titular de derechos fundamentales que pueden ser exigidos dentro o fuera de la empresa, ${ }^{6}$ no por su condición de trabajador sino por su calidad de persona. No obstante lo anterior, el grado de exigibilidad de estos derechos puede variar, como quiera que al momento de vincularse mediante un contrato de trabajo le son impuestas normas de comportamiento a las que se adhiere voluntariamente, limitando su libertad irrestricta (Melis, 2010, pp. 30-33).

Los derechos fundamentales inherentes al ser humano, de carácter irrenunciable, han sido denominados en la doctrina española como derechos fundamentales inespecíficos laborales, por ser aquellos que son atribuidos a todas las personas y que por lo tanto acompañan al individuo incluso en su relación de trabajo (Goñi, 2014, p. 8).

El empleador, al suscribir el contrato de trabajo con el trabajador, no solo asume un papel neutral frente a los derechos fundamentales, es decir, no asume solo un deber negativo respecto a no obstruir el ejercicio de un derecho, también se compromete a facilitar su ejercicio mediante acciones positivas (Bilbao, 1997, citado en Melis, 2010), sin embargo, tal y como se manifestará a continuación en el caso del respeto a

6 Los derechos fundamentales, concebidos como un "orden objetivo valorativo", según la Corte Constitucional irradian todo el ordenamiento jurídico (sentencia T-632 de 2007); como orden objetivo no admiten consideraciones apreciativas sino que se aplican de manera uniforme y primordial en todo tipo de relación, incluidas las de derecho privado. la intimidad, se ha reconocido su protección a través de la exclusión o la inacción del empleador, en tanto el núcleo del derecho incorpora la abstención de injerencia por parte de otro (Goñi, 2013, pp. 38-42).

\section{B. Del choque entre el derecho a la libertad de empresa (poder subordinante) y el derecho a la intimidad del trabajador}

El poder empresarial se encuentra intrínsecamente relacionado con el derecho a la libertad de empresa, en la medida en que esta última supone la libertad de participar en su fundación, mantenimiento y sostenimiento, estableciendo su planificación en función de sus recursos y las demandas del mercado (Fernández, 2013, p. 190). En consecuencia, cuando el empleador impone una orden o instrucción al trabajador está ejerciendo un derecho de contenido constitucional.

La pregunta que surge entonces frente a la imposición de órdenes, vigilancia y control de la empresa, es hasta dónde se pueden ejercitar dichas facultades sin lesionar derechos inespecíficos del trabajador. En este caso no podría hablarse de prevalencia de derechos, pues en principio se pensó que el contenido del derecho a la libertad de empresa estaba unido a derechos económicos, o de segunda generación, que debían ceder ante el interés tutelable de derechos de primera generación como el derecho a la intimidad del trabajador y su libertad de expresión. No obstante lo anterior, existe una posición doctrinaria que indica que la libertad de empre- 
sa "no es... un simple principio informador del orden económico... es un auténtico derecho y un derecho fundamental" (Fernández, p. 187). De conformidad con lo anterior, cuando existe colisión entre este tipo de derechos se está hablando de un enfrentamiento entre derechos de una misma entidad jurídica.

De esta forma, los derechos fundamentales constituyen un límite al ejercicio del poder subordinante frente al trabajador, así como el poder de dirección del empleador constituye un límite para el ejercicio irrestricto de los derechos de Ios trabajadores (sentencia del Tribunal Constitucional [stc 196/2004] del 15 de noviembre). Por lo que se puede concluir que la protección del derecho a la intimidad del trabajador no es tan intensa como la del individuo en su casa o habitación, y que en todo caso admite una ponderación con los intereses del empleador.

La intimidad como derecho no se limita entonces por una regulación normativa, sino porque existe otro derecho, el de libertad de empresa, que a su vez está contenido en el texto constitucional. $^{7}$

\section{ASPECTOS DE PROTECCIÓN DEL DERECHO A LA INTIMIDAD EN EL ÁMBITO LABORAL}

El derecho a la intimidad del trabajador tiene diferentes manifestaciones que se pueden evidenciar, incluso, desde el proceso de selección para aspirar a un empleo, hasta después de su terminación. Entonces, resulta interesante hacer un recuento a modo de ejemplo, de circunstancias en las que se ha reconocido este derecho en el derecho comparado, su alcance y límites. ${ }^{8}$

\section{A. De la protección a la intimidad al momento de aspirar a un cargo}

Al momento de suplir un cargo, el empleador para seleccionar su personal establece una serie de pruebas, entre las cuales se encuentran las de tipo cognoscitivo; las entrevistas grupales, personales, etc. El proceso de selección, que puede ser adelantado directamente por el empleador o por un tercero contratado, puede conllevar transgresiones al derecho a la intimidad en la medida en que la información que se pretenda obtener resulte intrínsecamente ligada al ámbito reservado del aspirante. En estricto sentido, las preguntas en un proceso de selección deberían corresponder a aquellas que es-

Como se precisó al inicio del escrito, el desarrollo jurisprudencial constituye una herramienta esencial para el análisis de la protección de este derecho, como quiera que no todos los países cuentan con una legislación específica al respecto. Así las cosas, existen ordenamientos como el colombiano en el que no se encuentra de manera expresa una consagración del derecho a la intimidad en el ámbito de la normatividad laboral, y otros como el español o el italiano en los que en su Estatuto del Trabajo sí se hace referencia. 
tén relacionadas con el ámbito laboral, sin embargo, existen factores de índole personal que permiten al empleador determinar la conveniencia o no de contratar a un candidato, de ahí que se entre a indagar con quién vive, cómo reacciona ante factores de estrés o por el momento más importante de su vida, para encontrar un perfil ajustado a la necesidad empresarial, que en la mayoría de los casos se estima con base en el nivel de productividad.

Pese a que el empleador, en principio, puede preguntar lo que desee al aspirante, como consecuencia de su poder para organizar su estructura empresarial, existen ciertos temas que han sido tratados con especial cuidado, como son los datos relativos a su ideología, religión o creencias, origen racial, salud y a la comisión anterior de infracciones penales o administrativas, ${ }^{9}$ como quiera que estos pueden generar discriminación en el empleo. En todo caso, el fin legítimo de la fase precontractual debe ser la valoración de la capacidad profesional de los candidatos, de manera que el empleador no tendría necesidad de conocerlos (De Vicente, 2010, pp. 305331).

Si este es el tratamiento que ameritan las preguntas formuladas de manera abierta por el empleador al aspirante a un trabajo, no podrían

9 Estos datos denominados sensibles, se encuentran contemplados en el artículo 7 de la Ley Orgánica española, reguladora del tratamiento automatizado de datos de carácter personal, y a su vez son dispuestos en la publicación Repertorio de recomendaciones prácticas de la olT. Protección de los datos personales de los trabajadores (oIT, 1977, p. 6 ), en la que se indica que información relativa a la vida sexual, ideas políticas y antecedentes penales únicamente pueden ser solicitados por el empleador, si guarda relación directa con una decisión en materia de empleo. entonces hacerse bajo el uso del polígrafo, pues a todas luces constituiría una violación al derecho a la intimidad, una extralimitación de los poderes del patrono que no resulta idónea, ni proporcional al fin buscado. ${ }^{10}$

No obstante lo anterior, en países como Colombia el uso de esta herramienta no está prohibido en el ordenamiento, según Concepto 116144/2012 del Ministerio del Trabajo, y en el caso de trabajadores de empresas de seguridad privada y de la Unidad Administrativa Especial de la Dirección de Impuestos y Aduanas Nacionales su uso se encuentra regulado. El Ministerio del Trabajo ha entendido que si se impone en un reglamento interno de trabajo la práctica de esa prueba para verificar el cumplimiento de los deberes del trabajador, la negativa de este a la prueba del polígrafo iría en contra del convencimiento y confianza que el empleador le debe tener y lo facultaría, incluso, para trasladarlo o para sancionar tal falta disciplinaria de conformidad con lo previsto en el mismo reglamento (Concepto 71526/2009: Ministerio de la Protección Social).

A contrario sensu, The Office of the Revisor of Statutes (2013) del estado de Minnesota en Estados Unidos, en el capítulo relativo al empleo de sus estatutos indica que se encuentra prohibido al empleador solicitar pruebas como el polígrafo, análisis de estrés en voz o cualquier otra que tenga por propósito probar la honesti-

10 En el Repertorio de recomendaciones prácticas de la olt (1977) se estipula que no se deben utilizar polígrafos, ni medios o procedimientos similares para comprobar la veracidad de las respuestas del trabajador (p. 6). 
dad del trabajador. Así mismo, el Departamento del Trabajo de Estados Unidos emitió la Employee Polygraph Protection Act of 1988, en la cual se prohíbe el uso del detector de mentiras tanto para la fase precontractual como durante el empleo, como también utilizar los resultados de estas pruebas en contra o para discriminar al candidato a un empleo.

De igual forma, en la página de la rama judicial del poder público de Puerto Rico, en referencia al numeral 8 del artículo 2 de la Constitución "Protección contra ataques a la honra, a la reputación y a la vida privada", se reconoce que el consentimiento para la prueba del polígrafo, otorgado por el trabajador, no permite concluir una renuncia al derecho a la intimidad, menos cuando este se encuentra en situación de desventaja en la medida que si no se somete a la prueba no podrá obtener el empleo, y aboga por que la balanza se incline en favor de los derechos del trabajador a la intimidad y la dignidad (Rama Judicial de Puerto Rico, s.f.).

Otro de los aspectos que debe ser analizado como una posible restricción al derecho a la intimidad al momento de acceder al empleo son las pruebas médicas exigidas, tales como la prueba de embarazo ${ }^{11}$ o la prueba de $\mathrm{VIH}^{12}$ En Colom-

11 En sentencia T-1219 de 2005, la Corte Constitucional de Colombia en cita de pronunciamiento anterior indicó que no se puede sacrificar el derecho a la libertad de maternidad, y en consecuencia de la intimidad de la mujer por la voluntad del empleador, por lo que el trato del empleador que busca investigar el estado de embarazo o no de la mujer para su acceso, permanencia o promoción constituye un acto de carácter ilegítimo e inconstitucional. De manera que las pruebas de embarazo para condicionar a la mujer acarrean la afectación del derecho a la intimidad de la empleada.

12 El tema de las pruebas de VIH será analizado más adelante en el aparte: Del derecho a la intimidad sobre condiciones de salud del trabajador. bia el caso de la prueba de embarazo ha sido resuelto a nivel jurisprudencial al señalar que no puede solicitarse en virtud del principio de no discriminación en el empleo y de la violación al derecho a la intimidad, salvo que la información requerida sea para examinar incompatibilidades insuperables respecto al cargo que se va a desempeñar, como por ejemplo, en ocupaciones con riesgo de incidir negativamente en la trabajadora o en el feto (CConst., sentencia T-1219 de 2005).

La visita domiciliaria es otro aspecto que merece revisarse desde la óptica del derecho a la intimidad. Si bien su objetivo es conocer información sobre la identidad de la persona, su relación con la familia, determinar la situación económica y estado de la vivienda (EAFIT, 2011), para establecer una relación entre lo que ha informado el aspirante en otros momentos del proceso de selección y su entorno real, inicialmente se señaló que el ámbito de garantía del poder de subordinación ostentado por el empleador estaba delimitado al lugar de trabajo. En este sentido, todo acto de vigilancia externo al ámbito empresarial como sería el domicilio del futuro trabajador, irá en contra de su derecho a la intimidad y, en consecuencia, las llamadas visitas domiciliarias están del todo proscritas.

\section{B. Del derecho a la intimidad en la ejecución del trabajo}

Durante el desarrollo de sus funciones el trabajador puede verse expuesto a intromisiones por parte del empleador, con el ánimo de verificar el cumplimiento de sus obligaciones, su pro- 
ductividad, el uso del tiempo exclusivamente en actividades laborales, controlar la seguridad de la empresa o de los otros operarios, entre otras finalidades legítimas que igualmente merecen una ponderación y unos límites por cuanto está en juego el derecho a la intimidad.

Una forma de proteger los derechos del trabajador y de determinar si la facultad de control del empleador sobre sus herramientas y las actividades que este realiza es excesiva, es efectuar un juicio de proporcionalidad sobre las medidas restrictivas y el derecho a la intimidad del trabajador (Sandoval, 2008, p. 12). El juicio de proporcionalidad, según nuestra Corte Constitucional, involucra tres criterios: el de necesidad de la medida, el de idoneidad y el de proporcionalidad en sí mismo.

En caso de que resulte justificada la vigilancia del sitio de trabajo, se deben seguir reglas tales como la supresión de información inútil, y limitar el acceso tanto a grabaciones como a los computadores de los trabajadores exclusivamente al personal de dirección en la empresa (Roqueta, 2010 p. 422) o al personal autorizado o previamente delegado por el empleador para tal efecto.

Como se había sugerido anteriormente, existe cierta tolerancia a que los trabajadores utilicen los computadores o los teléfonos del empleador para asuntos personales, sin embargo, para no crear una expectativa de privacidad del uso de estas herramientas de trabajo es frecuente encontrar dentro de las empresas políticas de uso y control sobre tales medios, como parte del ejercicio del control empresarial y del uso racional de estos (Roqueta, 2010, p. 432). En consecuencia, la implementación de una política sobre el uso adecuado de los recursos electrónicos o de otro tipo que suministre el empleador al trabajador, permite constituir causales para una justa causa de despido, y la imposición de límites razonables al derecho a la intimidad del trabajador. Dicha política se puede introducir en los contratos de trabajo, en los reglamentos o en un código de conducta en los que se determine qué acciones constituyen una falta grave y qué tipo de reiteración amerita una mayor sanción.

En caso de colisión entre el derecho de libertad de empresa del empleador y el derecho a la intimidad del trabajador lo lógico es que se emitan pronunciamientos de acuerdo con la normatividad vigente, sin embargo, como en la mayoría de países no existe una regulación al respecto, es usual que se acuda a la ponderación entre el derecho a la intimidad del trabajador y su dignidad vs. el abuso en la utilización de los medios de trabajo, la consecuente transgresión de buena fe contractual y abuso de confianza (a modo de ejemplo, el uso indebido de correo electrónico institucional para cosas personales) por parte del trabajador que conllevan a un incumplimiento contractual, como transgredir el deber de fidelidad frente al empleador, el uso adecuado de las herramientas de trabajo y el respeto por la buena fe. 


\section{Posibilidad de vigilar al trabajador en el} trabajo

A pesar de que los sistemas de control involucran mecanismos con vocación de permanencia que permiten obtener continuamente información sobre el comportamiento de los trabajadores (Martínez, 2002, citado en Roqueta, 2010, p. 410), de conformidad con la ort cuando el trabajador sea objeto de vigilancia debe conocer la razón que la motiva, ${ }^{13}$ el tiempo en que se aplica y el mecanismo utilizado, sin embargo, el empleador no tendrá dicho deber de información cuando tenga sospechas suficientes frente a la comisión de un hecho delictivo o una infracción grave, y solo se permitirá la vigilancia continua si se trata de proteger la salud o la seguridad (оIт, 1997, p. 8).

\subsection{Control audiovisual}

Para el caso de control audiovisual la doctrina española, apoyándose en diversos casos jurisprudenciales, indica que se consideran como finalidades legítimas para el uso de grabaciones: el control de riesgos al patrimonio de la empresa, o de los clientes, o del personal; el control a la seguridad de terceros, protegiendo su vida o integridad; la verificación del cumplimiento de las obligaciones laborales, como por ejemplo las faltas de puntualidad, falta de productividad (Roqueta, 2010, pp. 411-412), pero además de estar atadas a estos fines, según el Tribunal

13 Según The Employment Practices Code (pp. 64-73) como regla general ante un proceso de monitoreo los trabajadores deben estar enterados de la finalidad de la vigilancia, y de los beneficios que esta reporta. La excepción a esa regla termina en una vigilancia encubierta, por ejemplo, cuando existe sospecha de delito para obtener evidencia.
Constitucional debe determinarse si la medida es necesaria, si con ella resulta eficaz el fin deseado y si ofrece ventajas para el interés general sobre el interés particular (STC 151/2004), atendiendo a los principios de idoneidad, necesidad y proporcionalidad.

Ahora bien, los conceptos de proporcionalidad, necesidad e idoneidad han sido valorados dependiendo de las circunstancias concretas del caso, tal y como se podrá evidenciar en los siguientes precedentes. ${ }^{14}$

El Tribunal Laboral de Apelación del Reino Unido decidió el 16 de abril de 2013, el caso Condado de Swansea vs. Mr. D A Gayle, referente al control audiovisual por parte del empleador. Los fundamentos fácticos hacen relación a que el empleador del señor Gale, esto es el Condado de Swansea, ante sospechas de que el trabajador destinaba su tiempo de trabajo a actividades de ocio, decidió contratar un investigador privado para que lo siguiera y le tomara fotografías, sin su consentimiento. Mientras se suponía que el trabajador debía estar en su trabajo, fue filmado jugando squash repetidas veces, y con este material se procedió a despedirlo. El Tribunal de primera instancia encontró que la investigación encubierta contradecía el artículo 8 del Convenio Europeo de Derechos Humanos, que consagra el derecho a la intimidad, además de ser desproporcionada, más

14 En Chile, por ejemplo, la Dirección de Trabajo en Dictamen 4541/319, del 22.09.1998 (citado por Ugarte, 2011, p. 30), al examinar la posibilidad de un empleador para controlar el tiempo que se demoraban sus trabajadores en el baño, indicó que si bien la medida resultaba idónea para controlar el tiempo de trabajo y, en consecuencia, aspectos organizativos empresariales, no resultaba necesaria considerando que no era justificada la restricción al derecho a la intimidad del trabajador. 
aún cuando el empleador tenía una naturaleza pública, y en este sentido debía regirse por el Código de Protección de Datos en el Trabajo, razones por las que concluyó que a pesar de que sí existían hechos que motivaban el despido del trabajador, no se dio un despido con justa causa por la ignorancia de las obligaciones respecto a la protección de datos, y por la desproporcionalidad de la investigación.

La apelación centra el problema jurídico en determinar si al trabajador le asiste el derecho a la privacidad cuando está haciendo actos que defraudan a su empleador. El representante del Condado argumentó que no existió una transgresión del derecho a la intimidad pues la foto tomada por el investigador fue en un lugar público, mientras que el Tribunal de primera instancia arguyó que el trabajador tenía una expectativa razonable de privacidad en ese lugar.

El Tribunal, al examinar el contexto en el que fue tomada la fotografía, determinó que al tratarse de tiempo en el que se suponía debía estar laborando, el trabajador no podía tener la expectativa de privacidad pues durante este espacio el empleador tiene el derecho de saber dónde está el trabajador y qué está haciendo, de modo que no encontró ninguna violación al derecho a la intimidad contemplado en el artículo $8 \mathrm{del}$ Convenio Europeo, toda vez que este señala que pueden existir injerencias para proteger derechos de otros, que, en este caso, son los derechos del empleador, de conformidad con el contrato de trabajo suscrito y considerando que le estaban cobrando un salario sin recibir el servicio. Por consiguiente, concedió la apelación y concluyó que el señor Gayle fue despedido con justa causa.

En Colombia, respecto a los medios de control a través de video, la sentencia de la Corte Constitucional T-768 de 2008 examina el caso de un trabajador de un banco, quien al tener conocimiento de que estaba siendo monitoreado tapó el acceso de las cámaras con cajas de cartón. La empresa, luego de advertirle que no podía obstaculizar dicha vigilancia, decide instalar otro dispositivo desconocido por el actor, que permite filmarlo dándose muestras de afecto con una de sus compañeras, en las instalaciones de la empresa, durante el tiempo correspondiente a su hora de almuerzo. El trabajador fue despedido luego de habérsele seguido un proceso disciplinario. En discusión queda la legalidad del video y si se lesionó o no el derecho a la intimidad del trabajador.

Al respecto la Corte indica que el derecho a la intimidad en el ámbito laboral no tiene el mismo alcance que en el domicilio, porque en el primero existen actividades con repercusión social y no solo individual. Sin embargo, diferencia entre aquellos espacios que interesan exclusivamente al individuo y aquellos que interesan en la relación empresarial, e indica que las cámaras instaladas en lugares tales como locales sindicales, lugares de descanso, baños, vestuarios, o donde se tenga por fin filmar partes íntimas de una persona, violan el derecho a la intimidad, pero aquellas que son utilizadas para tomar medidas relacionadas con la vigilancia de la empresa, para que no se atente contra el derecho de propiedad o la seguridad, están permitidas. 
Frente al caso concreto, la Corte encuentra probado que al accionante se le había llamado la atención con anterioridad respecto a la obstrucción de las cámaras de vigilancia, hecho que demarcaba el incumplimiento de los deberes del trabajador; adicionalmente, encuentra proporcional el uso de cámaras en los bancos para proteger la seguridad de los trabajadores y de la institución, más cuando los trabajadores tenían conocimiento previo, razón por la que no se podría alegar que por el desconocimiento de la instalación de una nueva cámara la grabación hubiere sido ilícita. Por el contrario, resultó proporcional pues el comportamiento del trabajador de tapar el circuito de vigilancia permitía entrar en sospecha sobre su conducta. Por último, frente a la filmación en horas de descanso la Corte arguyó que tratándose de una grabación en el lugar de trabajo esta resultaba legal. Así las cosas, determinó que como para el despido se tuvo como causal la obstrucción de las cámaras y no acatar órdenes sobre seguridad y vigilancia en las instalaciones del Banco, este era justificado.

\subsection{Control sobre uso de herramientas de trabajo}

Para el desarrollo del objeto del contrato el empleador suministra al trabajador las herramientas de trabajo, de allí que le corresponda como obligación a este último darles el uso que corresponda. Sin embargo, en determinadas circunstancias ese uso puede involucrar una esfera de intimidad por parte del trabajador, aspecto sobre el cual también hay desarrollos para precisar cómo conciliar el uso personal de las herramientas de trabajo y el uso adecuado de estas sin extralimitarse.

En este específico caso se hará alusión a aqueIlos equipos, servicios y aplicaciones de uso en el trabajo que tienen la posibilidad de crear una esfera de intimidad para el trabajador: el computador, el correo electrónico y el teléfono. ${ }^{15}$

\section{- Control del computador en estricto sentido}

La doctrina española ha considerado que en el caso de instalar un sistema de monitoreo en el computador del trabajador, dicho sistema no debe tener vocación de controlar toda su actividad pues limitaría la intimidad al máximo nivel, sin embargo también sugiere poner en conocimiento del trabajador la vigilancia que se está haciendo, incluso señalando el acceso a las páginas web que este pueda visitar (Roqueta, 2010, pp. 437-438).

En analogía a cómo el empleador no puede registrar la gaveta o el escritorio correspondiente al trabajador por respeto a su derecho a la intimidad, tampoco podría de manera abusiva abrirle los archivos o el ordenador (Dacosta, 2003 , p. 12) sin poner en su conocimiento cualquier revisión que deba hacer.

En Colombia, la Corte Constitucional en la sentencia T-405 de 2007 examinó el caso de una

15 En el ámbito de vigilancia y control se debe distinguir entre el control de medios informáticos como la Internet y el uso de páginas web y las herramientas de interacción con terceros como son el correo electrónico, los teléfonos físicos y su uso, por cuanto en la primera hipótesis se trata de unos límites impuestos directamente al trabajador y en el segundo caso se involucran derechos de terceras personas (Martínez, 2005, citado en Roqueta, 2010 p. 420), pues como en todo tipo de comunicación existe un emisor y un receptor. 
trabajadora que había guardado en el computador asignado a ella por la empresa, en una carpeta personal abierta para sus documentos, unas fotos que según ella le tomó su hija, en las que aparecía desnuda. Su empleador las hizo públicas para demostrar que el ordenador era de carácter empresarial y en esa medida no podían existir imágenes de contenido personal en sus archivos. La Corte concluyó la violación a los derechos fundamentales de intimidad, honra, buen nombre y autodeterminación de la buena imagen de la accionante como consecuencia de la intromisión a información personal sin autorización del titular, por la divulgación, manipulación y exposición no autorizada de las imágenes.

Vale resaltar que en esa oportunidad la Corte examinó lo que la empresa consideraba un abuso en el uso de las herramientas de trabajo y una conducta inmoral, e indicó que el acceso a información perteneciente a la esfera personalísima del individuo no se justificaba aun cuando el computador fuera de la empresa, por cuanto toda extracción, manipulación y exhibición de esa información estaba vetada al hacer parte de una carpeta que aludía a documentos personales de la accionante.

\section{- Control de correos electrónicos y uso de teléfono}

En la facultad de vigilancia se encuentra la interceptación de comunicaciones efectuadas por medio de los teléfonos de la empresa y de los correos electrónicos institucionales, sin embargo esta atribución no opera de manera irrestricta. Las comunicaciones posibles de monitorear son aquellas que involucran aspectos meramente profesionales que han de ser identificados por el trabajador o por el empleador, ${ }^{16}$ de modo que las que guarden contenido personal no estarán expuestas a estos controles por la inviolabilidad de las comunicaciones (Roqueta, 2010, pp. 443-449).

Sobre los mensajes de correo institucional existe duda frente al derecho a la inviolabilidad de las comunicaciones. Algunos doctrinantes señalan que a semejanza de una carta sobre ellos recae el derecho al secreto de comunicaciones o el derecho a la intimidad, mientras otros indican que prima el derecho de propiedad de los instrumentos del empleador, y como el correo es una herramienta que facilita el trabajo, el empleador puede acceder libremente a su contenido, más aún cuando sobre él recae la responsabilidad por daños causados a terceros.

La vigilancia de los archivos enviados a través de un correo electrónico institucional obedece a la utilización del nombre de la empresa. En este sentido, si se causa un daño frente a terceros el responsable es el empleador y por eso tiene poder para controlar lo que se remite en su nombre (Dacosta, 2003, p. 12).

El Código Civil colombiano en el artículo 2349 atribuye a los empleadores la responsabilidad de los daños causados por los trabajadores con

16 Caso especial de interferencia de telecomunicaciones lo constituyen las empresas que desarrollan su objeto social por medio del teléfono, tales como los centros de llamadas (call center) o las empresas de telemarketing, en las que se encuentra justificado como quiera que solo de esta forma el empleador puede verificar el cumplimiento de las obligaciones laborales de los trabajadores (Roqueta, 2010, pp. 423424). 
ocasión del servicio prestado, lo que ha de suponer que el propiciado con los elementos de trabajo como es un correo electrónico será responsabilidad del empleador, salvo que, como lo indica el artículo, la conducta del trabajador fuera impropia o el empleador no tuviere forma de prever o impedir dicho daño, aplicando el cuidado ordinario y la autoridad competente. Así las cosas, el empleador responderá por los hechos dañinos del trabajador, cometidos en relación con el trabajo, salvo que empleando su dirección y vigilancia no pudiere prever el comportamiento del trabajador.

De conformidad con lo anterior, se acoge la posición que indica que el secreto de las comunicaciones cede cuando se usa el correo electrónico institucional, como consecuencia de la responsabilidad frente a terceros que tiene el empleador, cuya imagen y nombre resulta comprometido en virtud del uso de esa herramienta por él suministrada.

Es preciso resaltar que en la doctrina italiana no está legitimada la conducta de supervisión del empleador frente a medios como el correo electrónico, ni siquiera cuando se cuenta con el consentimiento del trabajador, porque entre otras cosas se debate la libertad del consentimiento (Pecorella y De ponti, 2010, p. 588).

Ahora bien, si nos encontramos en un campo eminentemente probatorio, cabe preguntarse si un correo electrónico cuyo emisor es el empleador puede ser aportado como prueba en su contra en un juicio donde el trabajador sea el accionante, cuando existe la inviolabilidad de comunicaciones y el derecho a la intimidad. La respuesta indica que no podría darse preeminencia al derecho a la intimidad del empleador so pena de socavar los derechos del trabajador, quien no cuenta con otras pruebas más que las obtenidas de los mismos medios de trabajo suministrados por el empleador; adicionalmente, se infiere que el tipo de información que se revela es de tipo semiprivado y en todo caso resulta oponible frente a la autoridad competente.

\section{Del derecho a la intimidad respecto a las condiciones de salud del trabajador}

La posibilidad del empleador de conocer el estado de salud de un trabajador está legitimada en el deber de protección y prevención de riesgos ocupacionales dentro de la empresa, en consecuencia, esta información deberá tenerse en cuenta para determinar si el trabajador puede ocupar un puesto específico, si cumple con los requisitos en materia de salud y seguridad en el empleo, o para determinar el derecho a prestaciones relativas al sistema de seguridad social (оІт, 1997, pp. 3-4).

La protección al derecho a no revelar aspectos de la salud del trabajador se encuentra asociada con que por ello no sea objeto de discriminación para acceder al empleo o para permanecer en este. De ahí que en la jurisprudencia colombiana se ha reconocido la facultad del trabajador para decidir si pone en conocimiento del empleador su estado de salud o no, sin perjuicio de que haya de seguir los reglamentos de higiene y salud ocupacional (CConst., sentencia T-513/2006). 
En la doctrina española, al igual que en la colombiana, se reconoce que en todo caso la información médica de carácter personal será conocida exclusivamente por el trabajador y por el médico tratante, mientras que al empresario únicamente se le pondrá de presente el reporte o resultados del estado de salud de los trabajadores, sin comunicar la afección que tenga, sino las recomendaciones que se deben adoptar en el lugar de trabajo (Roqueta, 2010, p. 458).

El examen de ingreso tiene por finalidad comprobar que el trabajador reúne las condiciones físicas necesarias para desempeñar su ocupación, adicionalmente proteger al empleador de que una enfermedad ya existente pueda ser catalogada como laboral y proteger al trabajador de posibles riesgos que involucre la actividad. En principio este examen debe ser practicado al trabajador, no obstante lo anterior, implica su consentimiento expreso.

En la STC 196/2004 del 15 de noviembre, el Tribunal Constitucional de España decidió una demanda formulada por una trabajadora a quien prestando sus servicios se le sometió a una prueba de orina que dio positiva en consumo de cannabis. Como consecuencia, la empresa dio por extinguida la relación laboral, a pesar de que no existió un documento suscrito por la trabajadora en el que diera su consentimiento expreso. El Tribunal examinó el tema del consentimiento eficaz para la práctica de la prueba y estableció que las pruebas resultan válidas siempre que cuenten con criterios de proporcionalidad al riesgo, indispensabilidad de las pruebas y la presencia de un interés preponderante del grupo social. Para el caso concreto, se indica que además del consentimiento debe existir una información correcta al trabajador que pueda inducirlo libremente a la práctica de las pruebas, para que entienda el alcance de estas, sus riesgos, resultados y contraindicaciones. Como en este caso la trabajadora no contó con esa información decidió reconocer su derecho a la intimidad personal. ${ }^{17}$

En Colombia existen diversas sentencias de la Corte Constitucional en las que se sigue la tesis de intimidad de los datos de salud del trabajador, sin perjuicio del deber de este de acatar instrucciones establecidas en los reglamentos de higiene y seguridad industrial (sentencia T-513/2006). A su vez, merece especial mención el caso de trabajadores portadores del VIH, en el sentido en que han sido reconocidos como sujetos de especial protección por cuanto su enfermedad los hace vulnerables a diferentes tipos de segregación (sentencia T-1218/2005). De esta forma y en concordancia con lo dispuesto en el Decreto 1543 de 1997, en el que se reglamenta el manejo de esta enfermedad inclusive en materia laboral, los trabajadores que la padecen no están obligados a informar a los empleadores esta situación, y en caso que la comuniquen, este último deberá ofrecer garantías laborales, sin que puedan tomarla como causal de despido.

17 El tema de las pruebas de alcohol y de drogas al trabajador durante la relación laboral también ha sido tratado desde la perspectiva del derecho a la intimidad, pero con límite en la seguridad de terceros y de otros trabajadores de la empresa, existiendo pronunciamientos al respecto, tales como las recomendaciones de la oIt frente al tratamiento de cuestiones relacionadas con el alcohol y drogas en el lugar de trabajo. 
- Posibilidad de exigir la historia clínica al momento de presentarse una incapacidad

En sentencia T-427 de 2013 la Corte Constitucional hace referencia a que en pronunciamientos reiterados ha indicado que las piezas que hacen parte de la historia clínica de un paciente se encuentran protegidas por el derecho a la intimidad. El caso concreto de las incapacidades se analizó en la sentencia T-669 de 2009, en la que se indicó que el empleador no puede solicitar junto con la incapacidad laboral la historia clínica, por su carácter de especial y reservado, que implica que solo pueda tener conocimiento de esta el paciente y los profesionales de la salud.

\section{De la información reportada en el expediente del trabajador}

Cuando el trabajador se vincula a una empresa, desde su inicio se le da apertura a un archivo contentivo de su hoja de vida, en el cual se almacena la forma de vinculación, las modificaciones del contrato, la constancia de recibo de reglamentos y políticas, promociones, acciones disciplinarias e información trascendental reportada en el transcurso de la relación laboral.

En principio tales archivos deben ser de conocimiento exclusivo del empleador o su representante, como por ejemplo del jefe de recursos humanos, y deben ser conocidos en la medida en que se adelante una acción específica frente al trabajador. El trabajador debe ser consciente de los documentos que se encuentran dentro de su expediente, pues estos han de ser oponibles y en caso de información contraria a la realidad tiene el derecho a que le sea rectificada.

Como quiera que el expediente incorpora una serie de datos del trabajador, a este le asiste el derecho de obtener copia de su expediente y de solicitar la modificación o la supresión de aquellos que sean inexactos o estén incompletos (ort, 1997, pp.12-13).

La Consejería de Empleo y Desarrollo Económico de Minnesota en el documento An Employer's Guide to Employment Law Issues in Minnesota incluye la obligación del empleador de permitir a los trabajadores el acceso a sus archivos personales cada seis meses mientras dure la relación laboral y hasta un año después de la desvinculación.

Para el caso colombiano, no existe una ley específica de protección de datos personales del trabajador en el empleo, motivo por el cual resulta aplicable la Ley general 1581 de $2012 .{ }^{18}$ Sin embargo, sí existe jurisprudencia referente a los datos contenidos en el sistema de información personal respecto a los funcionarios públicos. A manera de ejemplo: en la sentencia C-326 de 1997 la Corte Constitucional dictamina sobre la demanda de un ciudadano que estimaba la creación de un formato único de hoja de vida

18 La Ley 1581 de 2012 tiene por objeto desarrollar el derecho que les asiste a las personas para conocer, actualizar y rectificar las informaciones que hayan sido recogidas en bases de datos o archivos, lo que conlleva su aplicación en el ámbito del trabajo en el que el titular del derecho será el trabajador, y como tal podrá exigir que el tratamiento de sus datos tenga una finalidad legítima, se ajuste a las obligaciones legales y que estos no sean divulgados $u$ obtenidos sin su previa autorización; que su información sea completa, exacta, actualizada y reservada; y a que se tramite su reclamo frente a la información contenida quince días después de la fecha de recibo, entre otros. 
para quienes desempeñaran empleos públicos o prestaran servicios al Estado como violatorio del derecho a la intimidad, en razón a la conformación de bases de datos con la información de los contratistas y funcionarios. El máximo tribunal indica que los datos requeridos obedecen a aspectos académicos, títulos obtenidos, cargos desempeñados y situaciones que le permiten a la administración identificar si el aspirante se encuentra inmerso en una inhabilidad o incompatibilidad, por lo que estima que esto no se encuentra sustraído del conocimiento público, y es necesario para el proceso de selección laboral, así que no se ocasiona una violación del derecho a la intimidad.

\section{De la protección de la intimidad del trabajador a la terminación del contrato de trabajo}

Al momento de terminar el vínculo contractual puede presentarse una vulneración al derecho a la intimidad y a aquellos relacionados con el buen nombre, honra y dignidad, que muchas veces han sido definidos de forma homogénea, en la medida que terceras personas consulten al empleador datos sobre el trabajador, o este divulgue información relacionada con el comportamiento de este durante la relación laboral y las causales de terminación de esta.

En Colombia, la Corte Constitucional en sentencia T-482 de 2004 revisa el caso de una trabajadora que señala que su anterior empleador lesionó sus derechos al enviar a posibles empleadores una información en la que afirmaba que esta le adeudaba un dinero, lo que a su jui- cio impidió su vinculación a un nuevo empleo. La Corte precisa que al tratarse de una información real, aceptada por la accionante, de conocimiento de particulares, podía ser divulgada sin que esta circunstancia la afectara al punto de no poder trabajar, por lo que no encontró probada la lesión de derechos y en consecuencia no accedió al amparo solicitado.

Y en la sentencia T-634 de 2013 examina el caso de una masajista que a la terminación de su contrato solicitó la remoción de unas imágenes insinuantes de la página web y del Facebook del empleador (o contratante, pues no se define la relación por la cual fue contratada), que habían sido tomadas en vigencia de la relación laboral, al considerar que estas fotografías no obedecían a la imagen que quería presentar en sociedad, y producían pensamientos erróneos de lo que efectivamente hacía, como se deducía de los comentarios ofensivos y denigrantes que recibía a partir de la divulgación de tales imágenes. Por su parte, el accionado indicó que la trabajadora había prestado su consentimiento para la toma de las fotos y que ella era consciente del uso publicitario que estas tendrían.

Para determinar si había sido transgredido el derecho a la intimidad, la Corte indica que este comprende aspectos como el derecho a la proyección de la propia imagen; la protección de espacios privados, costumbres, prácticas sexuales y creencias religiosas; y cuando la imagen "reproduce actos o sucesos propios de la intimidad de una persona, [y] su difusión, en contra de su voluntad vulnera, en principio, el derecho fundamental a la intimidad" (CConst., senten- 
cia SU-089/1995) y señala que al momento de otorgar el consentimiento para la difusión de una imagen debe existir conocimiento sobre su finalidad, es decir, para qué va a ser utilizada, y, adicionalmente, no puede entenderse que otorgada la autorización esta queda vigente indefinidamente, pues la protección a la autodeterminación de la imagen permite que en cualquier tiempo el titular del derecho replantee la disposición de su imagen y retire su autorización.

\section{CONCLUSIONES}

Tanto el derecho a la libertad de empresa (del empleador) como el derecho a la intimidad (del trabajador) tienen protección legal en el marco de una relación de trabajo. Como quiera que se trate de derechos fundamentales, dicha protección se halla en la fijación de límites entre el poder subordinante y la restricción de ciertos espacios de intimidad del trabajador. Entre los límites fijados al empleador está el que no puede haber injerencias arbitrarias en la esfera íntima de los trabajadores, y que siempre deberá existir justificación en la finalidad, proporcionalidad, necesidad e idoneidad de la medida.

En este sentido, no existen reglas que permitan determinar objetiva y uniformemente si existe o no una vulneración de derechos de los trabajadores ante el control o vigilancia del empleador, y será el uso de los principios aplicados en cada caso los que permitan comprobar si se trata o no de una limitación proporcionada o de una transgresión de derechos fundamentales.
No obstante lo anterior, las recomendaciones, los actos de protección de datos en el empleo, y los mismos precedentes jurisprudenciales se encargan de establecer una serie de principios que han de ser seguidos como parámetros mínimos para no transgredir los derechos de los trabajadores, entre los que se encuentran: el poner de presente a los trabajadores las limitaciones del derecho a la intimidad; el tipo de control o monitoreo que se ejerce; el respeto por aspectos reservados del trabajador, por su intimidad y la garantía de no discriminación en el empleo por condiciones de salud, entre otros; así como establecer una forma de "consentimiento informado" que firme el trabajador para conciliar desde un primer momento el derecho de subordinación del empleador en medio de la relación laboral y sus propios derechos fundamentales que irradian todo tipo de relación.

Lo anterior no implica que el problema entre los límites del derecho a la intimidad y el derecho a la libertad de empresa se resuelva a partir del simple consentimiento del trabajador para permitir su restricción, pues como se indicó, ni siquiera los parámetros fijados en directrices y recomendaciones pueden determinar la frontera entre el ejercicio de uno u otro derecho. Por esto mismo, la solución se encuentra en la aplicación del test de proporcionalidad en cada caso concreto, lo que acarrea un problema para la unidad de criterio frente a cada uno de los factores determinantes en el test y frente a la autoridad administrativa o judicial que establezca la aplicación de los criterios de necesidad, proporcionalidad e idoneidad de la medida. 
En Colombia, pese al desarrollo doctrinario y jurisprudencial al respecto, no han llegado a examinarse todas las hipótesis anteriormente planteadas y habrá que acudir no solo a la aplicación del test de proporcionalidad sino a los desarrollos del derecho comparado que permiten vislumbrar diferentes soluciones al respecto.

\section{Referencias}

Bilbao Ubillos, J. M. (1997). La eficacia de los derechos fundamentales frente a particulares. Análisis de la jurisprudencia del Tribunal Constitucional. Madrid: Boletín Oficial del Estado/Centro de Estudios Políticos y Constitucionales.

Concepto 71526 de 2009. [Ministerio de la Protección Social]. Prueba del polígrafo. Marzo 12 de 2009.

Concepto 116144 de 2012. [Ministerio del Trabajo]. Uso del polígrafo en materia laboral. Junio 8 de 2012.

Conferencia Internacional Americana. (1948). Declaración Americana de los Derechos y Deberes del Hombre.

Consejo de Europa. Convenio Europeo de Derechos Humanos. Noviembre 4 de 1950.

Corte Constitucional. Sentencia SU-089 de 1995 (M. P.: Jorge Arango Mejía: marzo 1 de 1995).
Corte Constitucional. Sentencia C-326 de 1997

(M. P.: Fabio Morón Díaz: julio 10 de 1997).

Corte Constitucional. Sentencia T-482 de 2004

(M. P.: Álvaro Tafur Galvis: mayo 20 de 2004).

Corte Constitucional. Sentencia T-787 de 2004

(M. P.: Rodrigo Escobar Gil: agosto 18 de 2004)

Corte Constitucional. Sentencia T-1218 de 2005

(M. P.: Jaime Córdoba Triviño: noviembre 24 de 2005).

Corte Constitucional. Sentencia T-1219 de 2005

(M. P.: Jaime Córdoba Triviño: noviembre 24 de 2005).

Corte Constitucional. Sentencia T-513 de 2006

(M. P.: Álvaro Tafur Galvis: julio 6 de 2006).

Corte Constitucional. Sentencia T-405 de 2007

(M. P.: Jaime Córdoba Triviño: mayo 24 de 2007).

Corte Constitucional. Sentencia T-632 de 2007

(M. P.: Humberto Sierra Porto: agosto 15 de 2007).

Corte Constitucional. Sentencia T-768 de 2008

(M. P.: Clara Inés Vargas Hernández: julio 31 de 2008).

Corte Constitucional. Sentencia T-669 de 2009 (M. P.: Jorge Ignacio Pretelt Chaljub: septiembre 24 de 2009. 
Corte Constitucional. Sentencia C-540 de 2012

(M. P.: Jorge Iván Palacio Palacio: julio 12 de 2012).

Corte Constitucional. Sentencia T-427 de 2013 (M. P.: María Victoria Calle Correa: julio 10 de 2013).

Corte Constitucional. Sentencia T-634 de 2013 (M. P.: María Victoria Calle Correa: septiembre 13 de 2013).

Corte Europea de Derechos Humanos. (3 de abril de 2007). Caso de Copland vs. United Kingdom. (Application no. 62617/00).

Dacosta Herrera, A. F. (2003). El acceso a internet versus el poder de vigilancia de la empresa. Actualidad Laboral y Seguridad Social, (118), 10-15.

Decreto 1543 de 1997. [Ministerio de Salud]. Por el cual se reglamenta el manejo de la infección por el virus de inmunodeficiencia humana (VIH), el síndrome de la inmunodeficiencia adquirida (Sida) y las otras enfermedades de transmisión sexual (ETS). 12 de junio de 1997.

Escobar López, E, y Marulanda Otálvaro, L. F. (2004). El derecho a la intimidad (Segunda ed.). Bogotá: Ediciones Doctrina y Ley.

Estatuto del Trabajo de Italia. [Senado de la República]. Ley 300 de 1970. Junio 11 de 1970.

Fernández, T. R. (1988). Reflexiones constitucionales sobre la libertad de empresa. En Estu- dio en homenaje al doctor Héctor Fiz-Zamudio en sus treinta años como investigador de las ciencias jurídicas. Tomo I. Derecho constitucional, (págs. 181-207). Recuperado el 3 de marzo de 2014, de bilbio.jurídicas: http://biblio.juridicas.unam.mx/libros/2/641/13.pdf

Goñi Sein, J. L. (24 de enero de 2014). Los derechos fundamentales inespecíficos en la relación laboral individual: ¿necesidad de una reformulación? Recuperado el 7 de marzo de 2014, de fundación.usal: http://www.fundacion.usal.es/aedtss/images/stories/documentos/XXIII_Congreso_Nacional/01_Jose_ Luis_Gon\%CC\%83i.pdf

Gutiérrez Boada, J. D. (2001). Los límites entre la intimidad y la información. Bogotá: Universidad Externado de Colombia.

Hernández Rueda, L. (1997). Poder de dirección del empleador. En N. de Buen Lozano, Instituciones del derecho del trabajo y de la seguridad social (págs. 405-419). México: Academia Iberoamericana del Derecho del Trabajo y de la Seguridad Social/ Universidad Nacional Autónoma de México.

Information Comissioner's office [ıco]. (2011). The employment practices Code. UK: Autor.

Ley 1581 de 2012. [Congreso de Colombia]. Por la cual se dictan disposiciones generales para la protección de datos personales. Octubre 17 de 2012. DO. n. ${ }^{\circ} 48587$. 
Martínez Fons, D. (2002). El poder de control del empresario en la relación laboral. Madrid: Consejo Económico y Social.

Martínez Fons, D. (2005). El control empresarial del uso de las nuevas tecnologías en la empresa. En S. del Rey Guanter y M. Luque Parra, Relaciones Laborales y Nuevas Tecnologías. Madrid: La ley.

Melis Valencia, C. (2010). Los derechos fundamentales de los trabajadores como límites a los poderes empresariales (Segunda ed.). Santiago, Chile: Legal Publising.

Minnesota Department of Employment and Economic Development. (Enero de 2006). An Employer's Guide to Employment Law Issues in Minnesota. Recuperado el 7 de marzo de 2014, de lindquist.com: http://www.lindquist. com/files/Uploads/Documents/Employers_ Guide_Minnesota.pdf

Naciones Unidas [onu]. (Diciembre 10 de 1948). Declaración Universal de Derechos Humanos.

Naciones Unidas [onu]. (Diciembre 16 de 1966). Pacto Internacional de Derechos Civiles y Políticos.

Naciones Unidas [onu]. (Diciembre 18 de 2013). El derecho a la privacidad en la era digital. Res. A/RES/68/167.

Organización de Estados Americanos [OEA]. (Noviembre 22 de 1969). Convención Americana de Derechos Humanos.
Organización Internacional del Trabajo. (1997). Repertorio de recomendaciones prácticas de la оाт. Protección de los datos personales de Ios trabajadores. Ginebra: Oficina Internacional del Trabajo.

Pecorella, C. y De Ponti R. (2010). Privacy y control del correo y la navegación por la Red en el puesto de trabajo. En A. Jareño Leal (Coord.), La protección jurídica de la intimidad (págs. 583-607). Madrid: lustel.

Rama Judicial de Puerto Rico. (s.f.). Protección contra ataques a la honra, a la reputación y a la vida privada. Recuperado el 6 de marzo de 2014, de ramajudial: http://www.ramajudicial.pr/leyes/constitucion/articulo2-8.htm

Roqueta Buj, R. (2010). El derecho a la intimidad de los trabajadores y el control audiovisual del empresario. En A. Jareño Leal (Coord.), La protección jurídica de la intimidad (págs. 405462). Madrid: Iustel.

Sandoval, C. M. (2008). Poder disciplinario y nuevas tecnologías. Actualidad Laboral y Seguridad Social, (146), 10-15.

The Office of the Revisor of Statutes. (2013). 2013 Minnesota Statutes. Recuperado el 6 de marzo de 2014 de revisor.mn.gov: https://www.revisor.mn.gov/search/doc_result. php?search=stat\&keyword_type=all\&keywor d=2013+Minnesota+Statutes\&stat=1\&stat_ year1=2013\&stat_year2 $=2013$ 
Tribunal Constitucional de España. Sentencia 151/ 2004 (septiembre 20 de 2004).

Tribunal Constitucional de España. Sentencia 196/2004 (noviembre 15 de 2004).

Ugarte Cataldo, J. L. (2011). Privacidad, trabajo y derechos fundamentales. Estudios Constitucionales, IX(1), 13-35.

United Kingdom Employment Appeal Tribunal. (2013). City and Country of Swansea Appellant vs. Mr D A Gayle Respondent. Recuperado el 19 de febrero de 2014, de bailli: http://www.bailii. org/uk/cases/UKEAT/2013/0501_12_1604. $\mathrm{html}$

Universidad EAFIT. (3 de mayo de 2011). Una visita para conocer el entorno del aspirante. Recuperado el 6 de marzo de 2014, de eafit: http://www.eafit.edu.co/egresados/noticias/2011/Paginas/una-visita-para-conocerel-entorno-del-aspirante.aspx 